\title{
Development of Decontamination Treatment Techniques for Dry Powder Foods by Atmospheric-Pressure Nonequilibrium DC Pulse Discharge Plasma Jet
}

\author{
Toshifumi Yuji $\mathbb{D}^{1},{ }^{1}$ Kenichi Nakabayashi, ${ }^{1}$ Hiroyuki Kinoshita, ${ }^{2}$ Narong Mungkung $\mathbb{D}^{3},{ }^{3}$ \\ Yoshifumi Suzaki, ${ }^{4}$ Sarizam Mamat, ${ }^{5}$ and Hiroshi Akatsuka $\oplus^{6}$ \\ ${ }^{1}$ Faculty of Education, University of Miyazaki, 1-1, Gakuenkibanadai-nishi, Miyazaki 8892192, Japan \\ ${ }^{2}$ Department of Mechanical Design Systems Engineering, University of Miyazaki, 1-1, Gakuenkibanadai-nishi, \\ Miyazaki 8892192, Japan \\ ${ }^{3}$ Department of Electrical Technology Education, King Mongkut's University of Technology, 126 Pracha Uthit Rd, Bang Mot, \\ Thung Khru, Bangkok 10140, Thailand \\ ${ }^{4}$ Department of Advanced Materials Science, Kagawa University, 1-1 Saiwai-cho, Takamatsu-shi, Kagawa 7608521, Japan \\ ${ }^{5}$ Advanced Materials Research Cluster, Faculty of Bioengineering and Technology, Universiti Malaysia Kelantan, Jeli 17600, \\ Kelantan, Malaysia \\ ${ }^{6}$ Institute of Innovative Research, Tokyo Institute of Technology, 2-12-1 Ookayama, Meguro-ku, Tokyo 1528550, Japan
}

Correspondence should be addressed to Narong Mungkung; narong_kmutt@hotmail.com

Received 20 July 2020; Revised 11 May 2021; Accepted 13 July 2021; Published 26 July 2021

Academic Editor: Luca Campone

Copyright (c) 2021 Toshifumi Yuji et al. This is an open access article distributed under the Creative Commons Attribution License, which permits unrestricted use, distribution, and reproduction in any medium, provided the original work is properly cited.

\begin{abstract}
Dry powder food ingredients imported to Japan contain large amounts of viable bacteria and coliform bacteria, and we need a simple, low-cost, dry nonthermal decontamination method without spoiling nutrients, color, fragrance, and flavor. In this study, it is shown that the decontamination performance against viable bacteria and coliform bacteria is proportional to the plasma irradiation time when $\mathrm{OH}$ and $\mathrm{O}_{3}$ radicals are incident on the dry powder food ingredients placed in an atmospheric-pressure nonequilibrium DC pulse discharge $\mathrm{Ar}+\mathrm{O}_{2}$ mixture gas plasma jet. Our study revealed that there is a correlation between the plasma irradiation time and DC pulse frequency increase and the decontamination effect on the general bacterial count.
\end{abstract}

\section{Introduction}

Introduced in 1991 by the Japanese government, the FOSHU (Foods for Specified Health Use) system [1-5] expanded the food market including supplements and Chinese herbal medicine. The supply of food ingredients including supplements and Chinese herbal medicine greatly depends on both domestic production and importation. The companies taking part in FOSHU market are lately experiencing problems-especially food poisoning caused by orally transmitted bacteria-with large amounts of viable bacteria and coliform bacteria in the dry powder food ingredients imported from abroad. As a means to sterilize viable bacteria and coliform bacteria, the facilities for producing FOSHU adopt hot air process or steam process [6-8], which causes, due to heat or steam, an adverse effect on nutrients, color, fragrance, and flavor. To solve this problem, a simple, lowcost, dry nonthermal decontamination method is needed without affecting the qualities such as nutrients, color, fragrance, and flavor in the facilities producing FOSHU using dry powder food ingredients containing viable bacteria and coliform bacteria.

To this, the authors have succeeded in introducing the use of the laser-induced fluorescence method [9-12] - which is often said to be difficult-to observe the $\mathrm{OH}$ and $\mathrm{O}_{3}$ radicals emitted from oxygen gas using atmospheric-pressure nonequilibrium discharge plasma. Based on the observations of radicals in this research, it was found that the 
existence of $\mathrm{OH}$ radicals was verified at a position of $45 \mathrm{~mm}$ downstream from the plasma torch nozzle [13]. The techniques using $\mathrm{OH}$ radicals, attracting attention as sterilization technology, have often been reported in the medical field [14-17]. Also, Cheng et al. worked on the plasma using equivalent total oxidation potential, which is based on the oxidation potential of the role of reactive oxygen nitrogen species. To evaluate the feasibility of the equivalent total oxidation potential dose, a fitting model is developed, and the bacterial reduction factor is selected as the indicator of plasma's biological effects in the latest research [18].

In this study, to sterilize viable bacteria and coliform bacteria without spoiling nutrients, color, fragrance, and flavor, a new methodology using atmospheric-pressure nonequilibrium DC pulse discharge plasma is proposed for use at low temperatures so as to perform the irradiation of $\mathrm{OH}$ radicals to dry powder food ingredients. Therefore, it is shown that the decontamination effect against viable bacteria and coliform bacteria in the dry powder food ingredients increases proportionally to the irradiation time and pulse frequency of the plasma irradiated using an atmospheric-pressure nonequilibrium DC pulse discharge $\mathrm{Ar}+\mathrm{O}_{2}$ mixture gas plasma jet generated by high-frequency DC pulsed power supply.

\section{Experimental Setup}

Figure 1 shows a schematic of the experimental setup. As shown in the figure, plasma was generated using a DC pulse power source for plasma generation (PHF-1K-W; Haiden Laboratory Inc.) and atmospheric-pressure nonequilibrium DC pulse discharge plasma jet electrodes (PJ-6K; Haiden Laboratory Inc.) with a $1.0-10.0 \mathrm{kHz}$ pulse frequency and $1.0 \mathrm{~kW}$ plasma power. The gas mixture of argon $(5.0 \mathrm{~L} / \mathrm{min})$ and oxygen $(0.1-1.0 \mathrm{~L} / \mathrm{min})$ was used for the plasma. The atmospheric-pressure nonequilibrium DC pulse discharge plasma jet electrodes can generate dielectric barrier electric discharge over a relatively large area of the upstream part of the torch and efficiently generate active species. In addition, arc discharge is generated in the downstream torch where the dielectric is not present.

Figure 2 shows the oscillogram of the voltage waveforms (pulse frequency: $10 \mathrm{kHz}$ and input power:300 W) with argon $(5.0 \mathrm{~L} / \mathrm{min})$ and oxygen $(0.1-1.0 \mathrm{~L} / \mathrm{min})$ gas. The system first generates silent discharge using the high-frequency component (rising edge) of a single pulse applied by the DC pulse power source and then generates an arc discharge when the pulse voltage reaches a peak; since the voltage is applied as a pulse wave, the discharge time is as small as several $\mu \mathrm{s}$, and electromagnetic pumping is weak compared with the DC pulse discharge plasma jet [19]. The plasma torch nozzle is made up of a titanium rod $(4.0 \mathrm{~mm}$ $\mathrm{OD} \times 10 \mathrm{~mm}$ length) at the center of body and is covered with an SUS pipe $(36 \mathrm{~mm}$ OD $\times 30 \mathrm{~mm}$ ID $\times 87 \mathrm{~mm}$ length $)$. A quartz tube $(26 \mathrm{~mm} \mathrm{OD} \times 24 \mathrm{~mm}$ ID $\times 87 \mathrm{~mm}$ length $)$ is placed between the titanium rod and the SUS pipe at the upper part of plasma torch nozzle. The plasma gas flow into the torch is controlled at $5.0 \mathrm{~L} / \mathrm{min}$, and at the nozzle exit, the speed is increased by means of a small diameter; active species generated by silent discharge in the upstream part of the torch efficiently jets out with the gas force [20] and the electromagnetic pumping action [21]. The heating of the electrodes is prevented, and the plasma temperature is kept relatively low because the plasma is supplied by intermittently applying the voltage and the plasma gas flow rate is relatively high $[22,23]$.

The plasma jet electrodes used in this experiment use argon gas, which is noble gas, to stably generate plasma. Due to the structure of the electrodes, we cannot introduce oxygen gas at the flow rate exceeding $20 \%$ of the flow rate of the noble gas. As a preparation of this experiment, we set a stage of aluminium sheet at the distance of $50 \mathrm{~mm}$ at the downstream section of the nozzle tip of the electrode. The measurement of the temperature on the stage substrate using type-E thermocouples revealed the substrate temperature around $30^{\circ} \mathrm{C}$. At the same time, we installed an ultraviolet lamp at the same height as the tip of the electrode nozzle to verify the decontamination and disinfection effect of the light. However, we observed no change in the general viable bacteria count, and coliform bacteria verification test showed simply positive with no significant effect by the light.

Figure 3 shows the fine powder of mulberry leaves, which is used as dry powder food ingredients in the experiment. The general viable bacteria count in $1.0 \mathrm{~g}$ of the mulberry leaves used in the experiment is $3.6 \times 10^{5}$ (g/counts), showing positive result in the coliform bacteria verification test. Generally, the general bacterial count-the count of mesophilic aerobic bacteria such as Salmonella and enterohemorrhagic E. coli O157 [24-27], which grow under certain conditions - is generally used as a representative index of the level of microbial food contamination for the comprehensive evaluation of safety, storage stability, and hygienic handling of food. In addition, coliform bacteria are non-spore-forming Gram-negative bacilli-without specifying the types of bacteria-covering all types of aerobic or facultative anaerobes that break lactose into acid and gas [28].

Note that the fine powder of mulberry leaves, used in dietary supplements such as green juice, contains carotene, calcium, vitamin B1, and iron, rich with protein, minerals, and nutrients such as dietary fibers and has an effect to improve blood cholesterol levels and neutral fat [29]. In the experiment, the fine powder of mulberry leaves $(20 \mathrm{~g})$ was put in a beaker of $50 \mathrm{~mL}$ and placed at the distance of $15 \mathrm{~mm}$ from the nozzle tip so that the surface of fine powder is not scattered by the plasma gas coming from the plasma electrode. Hence, we were previously able to conduct surface treatment of polymer film using atmospheric-pressure nonequilibrium DC pulse discharge plasma jet at a position of $35 \mathrm{~mm}$ from the plasma torch nozzle using laser-induced fluorescence method, which made it possible to confirm the effect of surface treatment based on the influence of radicals [30]. The plasma irradiation time was set to one minute, five minutes, and ten minutes, and the fine powder was stirred every two minutes so that the plasma was irradiated on the whole area of the fine powder. The plasma irradiation time on the 


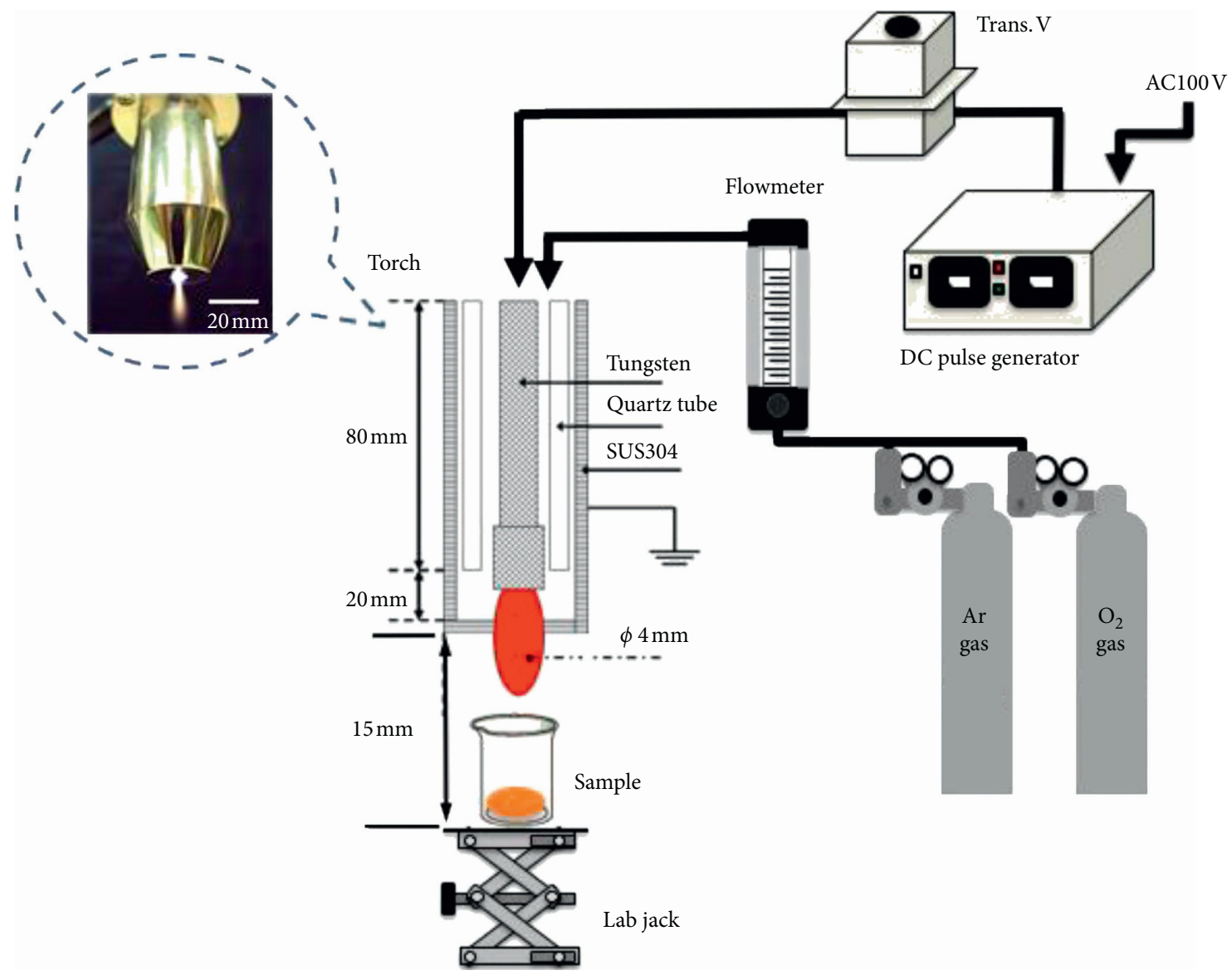

FIGURE 1: Schematic of the experimental setup.

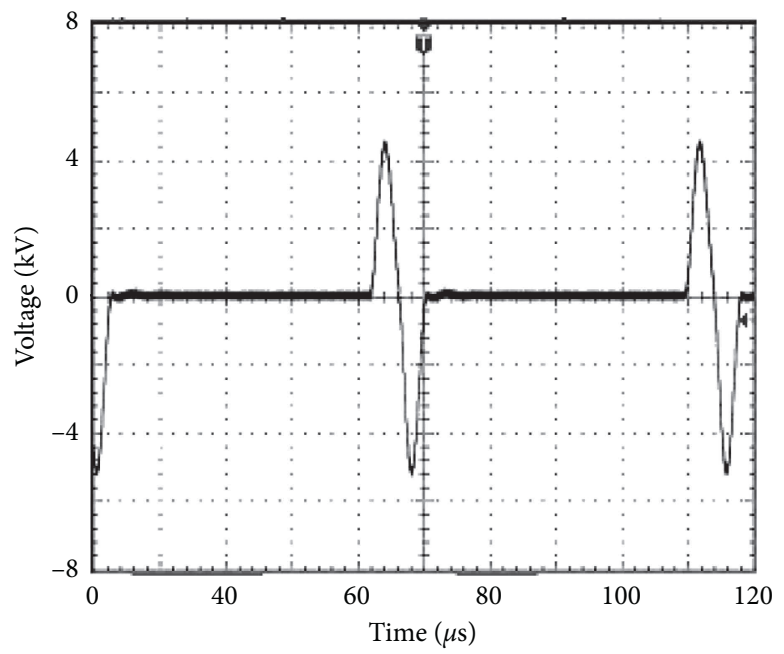

Figure 2: The oscillogram of the voltage waveforms (pulse frequency: $10 \mathrm{kHz}$ and plasma power $300 \mathrm{~W}$ ).

fine powder of mulberry leaves was between 1 and 10 minutes. For plasma irradiation time of more than 2 minutes, we mixed the mulberry leaves' fine powder for about 5 seconds every 2 minutes since the powder diameter is very small at $0.5 \mathrm{~mm}$ or smaller, so that the plasma will be irradiated uniformly over the mulberry leaves' fine powder in the beaker. The number of general bacteria and coliform bacteria was counted by the $3 \mathrm{M}^{\mathrm{TM}}$ Petrifilm $^{\mathrm{TM}}$ (3M Company) method [31] with 100-time diluted solution using $3 \mathrm{M}^{\mathrm{TM}}$ Petrifilm ${ }^{\mathrm{TM}}$ AC medium for general bacteria and $3 \mathrm{M}^{\mathrm{TM}}$ Petrifilm ${ }^{\mathrm{TM}} \mathrm{CC}$ medium for coliform bacteria. 


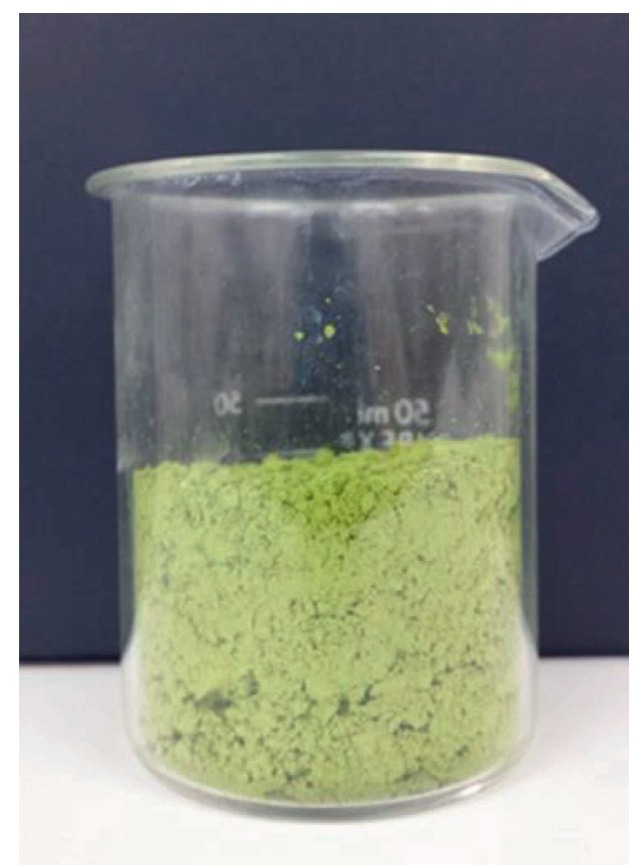

Figure 3: Picture of dry food powder (in beaker).

\section{Results and Discussion}

Figure 4 shows the distribution of general bacteria per gram of fine powder of mulberry leaves in the $3 \mathrm{M}^{\mathrm{TM}}$ Petrifilm ${ }^{\mathrm{TM}} \mathrm{AC}$ medium evaluated by the $3 \mathrm{M}^{\mathrm{TM}}$ Petrifilm ${ }^{\mathrm{TM}}$ method in the plasma processing time window on $10 \mathrm{kHz}$ pulse frequency, and a gas mixture of Ar gas with a steady flow rate of $5.0 \mathrm{~L} /$ min and $\mathrm{O}_{2}$ gas with a flow rate $1.0 \mathrm{~L} / \mathrm{min}$ is used as the plasma gas, and $10 \mathrm{kHz}$ of pulse frequency and $100 \mathrm{~W}$ plasma power were preferred. The figure clearly shows that the red dot colonies in the film medium decrease with the plasma irradiation time.

Figure 5 shows the relationship between the general bacterial count per gram of fine powder of mulberry leaves in the $3 \mathrm{M}^{\mathrm{TM}}$ Petrifilm ${ }^{\mathrm{TM}} \mathrm{AC}$ medium and the plasma irradiation time window on $10 \mathrm{kHz}$ pulse frequency, and a gas mixture of Ar gas with a steady flow rate of $5.0 \mathrm{~L} / \mathrm{min}$ and $\mathrm{O}_{2}$ gas with a flow rate $1.0 \mathrm{~L} / \mathrm{min}$ is used as the plasma gas and also the distribution of coliform bacteria per gram of fine powder of mulberry leaves in the $3 \mathrm{M}^{\mathrm{TM}}$ Petrifilm ${ }^{\mathrm{TM}} \mathrm{CC}$ medium over the entire plasma processing time evaluated by the $3 \mathrm{M}^{\mathrm{rM}}$ Petrifilm ${ }^{\mathrm{TM}}$ method. In Figure 5, a $10 \mathrm{kHz}$ of pulse frequency and $100 \mathrm{~W}$ plasma power is used. It also shows that the general bacterial count is $1.8 \times 10^{5}(\mathrm{~g})$ if the plasma processing time is one minute and $8.0 \times 10^{4}(\mathrm{~g})$ in ten minutes, indicating that half of the bacteria are killed.

Figure 6 shows the relation between changes in the DC pulse frequency and oxygen ratio in the plasma gas obtained with $3 \mathrm{M}^{\mathrm{TM}}$ Petrifilm ${ }^{\mathrm{TM}}$ method and the general bacterial count per $1.0 \mathrm{~g}$ of fine mulberry leaf powder inspected with the $3 \mathrm{M}^{\mathrm{TM}}$ Petrifilm ${ }^{\mathrm{TM}}$ AC medium, keeping the gas flow rate of Ar constant $(5.0 \mathrm{~L} / \mathrm{min})$ and that of $\mathrm{O}_{2}$ in the range from 0.1 to $1.0 \mathrm{~L} / \mathrm{min}$, in which the input power was $100 \mathrm{~W}$ and the plasma treatment time was $10.0 \mathrm{~min}$. From Figure 6, the general bacterial count was $1.8 \times 10^{4}(\mathrm{~g})$ at the DC pulse frequency of $1.0 \mathrm{kHz}$ and it decreased to $8.0 \times 10^{4}(\mathrm{~g})$ at the DC pulse frequency of $5.0 \mathrm{kHz}$, almost half of the count at $1.0 \mathrm{kHz}$, which confirms the sterilization effect. At the same time, as the oxygen ratio in the plasma gas increases, the general bacterial count decreased, confirming the enhanced sterilization effect.

In the atmospheric-pressure nonequilibrium discharge plasma processing of the fine powder of mulberry leaves, the general bacteria and coliform bacteria are sterilized because during the process that the $\mathrm{Ar}+\mathrm{O}_{2}$ mixture gas mixture in the atmospheric-pressure nonequilibrium discharge plasma reacts with the electrons emitted from the plasma or the atmospheric moisture, oxygen and water molecules are detached to produce oxygen atoms and, as discussed in earlier reports, $\mathrm{OH}$ and $\mathrm{O}_{3}$ radicals are created with a strong oxidizing and decontaminating power.

Plasma treatment of the fine mulberry leaf powder reduced the number of general bacteria counts and contributed to the negative result of coliform bacteria verification test. This revealed that the plasma treatment has the decontamination effect. The major factor is the electrons emitted in the plasma and oxygen radicals derived from oxygen gas reacting with vapor in the air to detach oxygen molecules and water molecules to generate oxygen atoms. This produces ozone and $\mathrm{OH}$ radicals with strong oxidizing power and high sterilization effect. We believe that these radicals react with the general bacteria and coliform bacteria adhered to fine mulberry leaves' powder to produce decontamination and disinfection effect.

The chemical reaction formulas (1)-(4) [32, 33] are shown for the creation of $\mathrm{O}_{3}$ in the atmospheric-pressure nonequilibrium discharge DC pulse plasma jet, where $M$ is any neutral: 


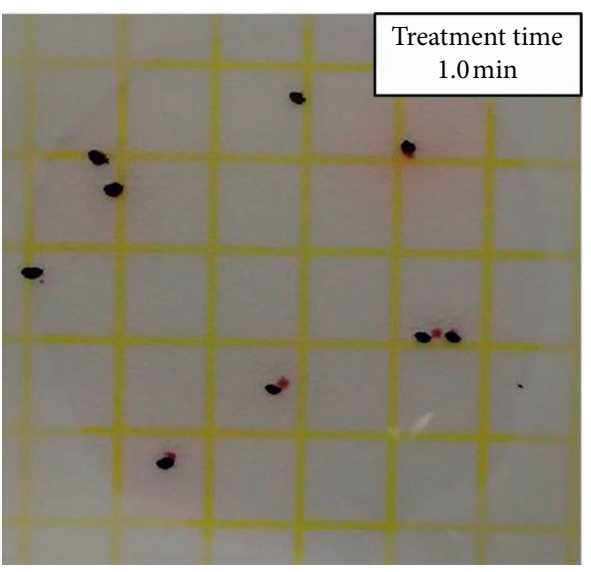

(a)

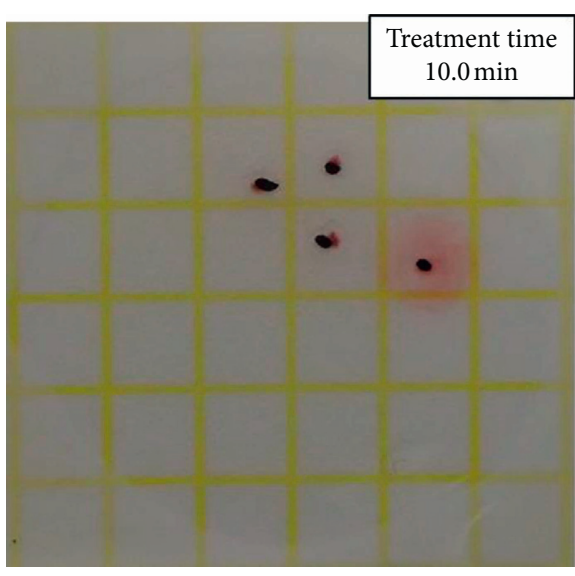

(b)

Figure 4: Picture of $3 \mathrm{M}^{\mathrm{TM}}$ Petrifilm ${ }^{\mathrm{TM}}$ AC Staph Express Count Plate (bacteria per gram) in mulberry. Treatment time: (a) 1.0 min; (b) $10.0 \mathrm{~min}$.

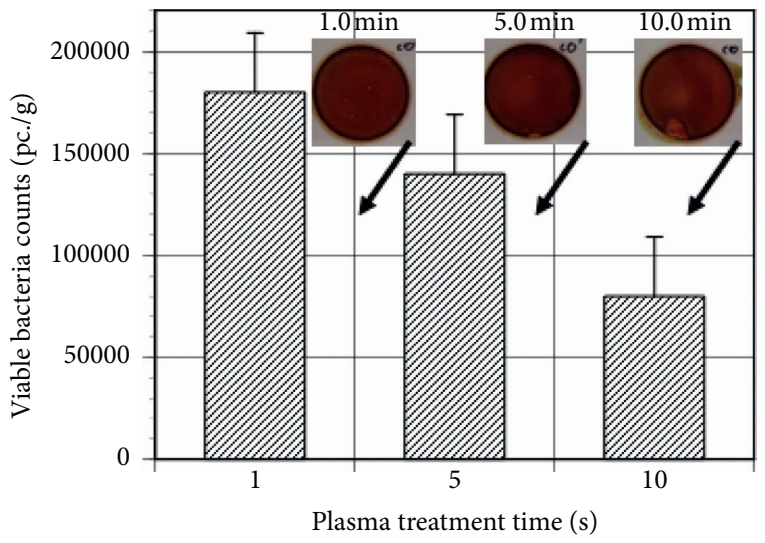

Figure 5: Relationship between plasma treatment time and variety bacteria count and $3 \mathrm{M}^{\mathrm{TM}}$ Petrifilm ${ }^{\mathrm{TM}}$ CC Staph Express Count Plate (in mulberry).

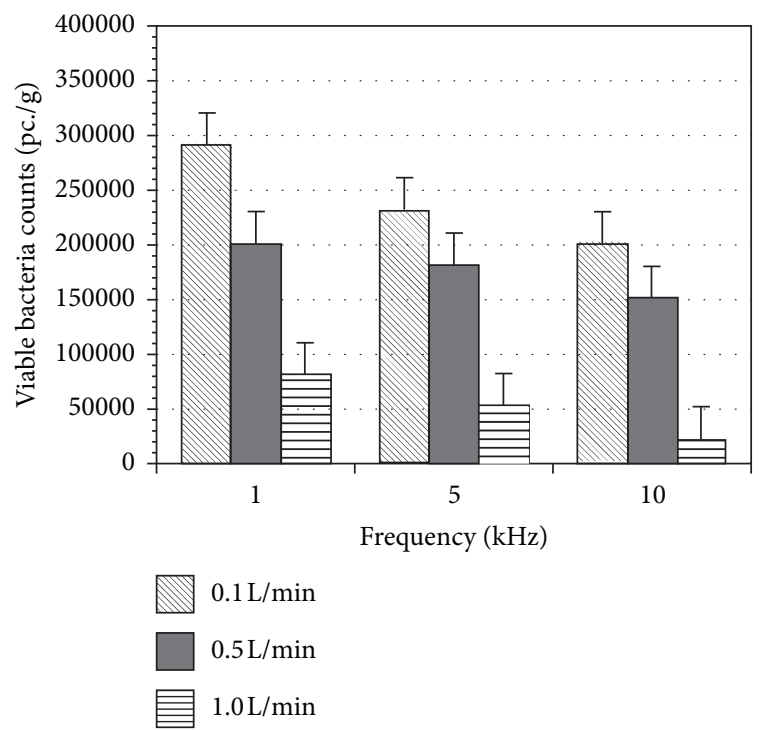

FIGURE 6: Relationship between DC pulse frequency and variety bacteria count and oxygen gas ratio in Staph Express Count Plate on $3 \mathrm{M}^{\mathrm{TM}}$ Petrifilm ${ }^{\mathrm{TM}} \mathrm{CC}$ (in mulberry).

$$
\begin{gathered}
\mathrm{O}_{2}+e \longrightarrow \mathrm{O}_{2}^{+}+2 e \\
\mathrm{O}_{2}+e \longrightarrow 2 \mathrm{O}+e \\
\mathrm{O}_{2}+\mathrm{O} \longrightarrow \mathrm{O}_{3} \\
\mathrm{O}+\mathrm{O}_{2}+M \longrightarrow \mathrm{O}_{3}+M
\end{gathered}
$$

Although short-lived, $\mathrm{OH}$ radicals with a strong oxidizing and decontaminating power are continually generated as far as ozone and water molecules exist in the atmosphere. We assume that they greatly contribute to the decontamination and inactivation of bacteria. The mechanism of the creation of $\mathrm{OH}$ radicals is shown as follows [34]:

$$
\begin{aligned}
e+\mathrm{H}_{2} \mathrm{O} & \longrightarrow e+\cdot \mathrm{OH}+\mathrm{H} \\
e+\mathrm{O}_{2} & \longrightarrow e+\mathrm{O}+\mathrm{O} \\
e+\mathrm{H}_{2} \mathrm{O} & \longrightarrow \cdot \mathrm{OH}+\cdot \mathrm{OH}+\mathrm{H} \\
\mathrm{O}_{3}+\mathrm{H}_{2} \mathrm{O} & \longrightarrow \cdot \mathrm{OH}+\cdot \mathrm{OH}+\mathrm{O}_{2}
\end{aligned}
$$

\section{Conclusion}

This study confirmed that using atmospheric-pressure nonequilibrium DC pulse discharge with $\mathrm{Ar}+\mathrm{O}_{2}$ mixture plasma gas and irradiating the plasma on the dry powder food improved the decontamination processing capacity on general bacterial count with the bacterial count reduced to $50 \%$ when the irradiation time was increased by 10 . It also revealed that increasing the plasma irradiation time, pulse frequency, and the oxygen gas ratio in the plasma gas further improved the decontamination processing capacity on general bacterial count. The decontamination effect on coliform bacteria was also confirmed. The results suggest that $\mathrm{OH}$ and $\mathrm{O}_{3}$ radicals with a strong oxidizing and decontaminating power, created by the reaction between plasma radicals and atmospheric moisture, have a great decontamination effect against both general bacteria and coliform 
bacteria. $\mathrm{O}_{3}$ and other active species generated in the reacting space play major roles during the degradation process. The atmospheric-pressure nonequilibrium DC pulse discharge plasma process was analyzed. The radical species $\left(\mathrm{OH}, \mathrm{O}_{3}\right.$, etc.) were produced in the gas phase and transferred to the air, where they reacted with the substances in it.

In the future, in pursuit of superior performance on dry powder food ingredients, we will examine the plasma gas species and irradiation techniques to complete the dry nonthermal decontamination method using an atmospheric-pressure nonequilibrium DC pulse discharge plasma jet.

\section{Data Availability}

The datasets during and/or analysed during the current study are available from the corresponding author upon reasonable request.

\section{Conflicts of Interest}

The authors declare that they have no conflicts of interest.

\section{Acknowledgments}

The author would like to thank Mr. J. Yamaki and Mr. M. Onomura of Seishin Enterprise Co., Ltd., for their valuable discussions. This work was supported by King Monkut's University of Technology Thonburi (KMUTT), Thailand; under the project of the Research, Innovation, and Partnership Office with Faculty of Industrial Education and Technology Research Funding.

\section{References}

[1] K. Yamada, N. Sato-Mito, J. Nagata, and K. Umegaki, "Health claim evidence requirements in Japan," The Journal of $\mathrm{Nu}$ trition, vol. 138, no. 6, pp. 1192S-1198S, 2008.

[2] M. Ono and A. Ono, "Impacts of the FoSHU (food for specified health uses) system on food evaluations in Japan," Journal of Consumer Marketing, vol. 32, no. 7, pp. 542-550, 2015.

[3] K. Maruyama, F. Kihara-Negishi, N. Ohkura, Y. Nakamura, M. Nasui, and M. Saito, "Simultaneous determination of catechins and caffeine in green tea-based beverages and foods for specified health uses," Food and Nutrition Sciences, vol. 8, no. 3, pp. 316-325, 2017.

[4] T. Chiba, Y. Sato, S. Suzuki, and K. Umegaki, "Concomitant use of medicines with food for specified health uses," Nippon Eiyo Shokuryo Gakkaishi, vol. 68, no. 4, pp. 147-155, 2015, (in Japanese).

[5] I. Murakami, H. Hosono, S. Suzuki, J. Kurihara, F. Itagaki, and M. Watanabe, "Enhancement or suppression of ACE inhibitory activity by a mixture of tea and foods for specified health uses (FOSHU) that are marketed as "support for normal blood pressure," International Scholarly Research Notices, vol. 2011, Article ID 712196, 4 pages, 2011.

[6] T. Tsuchido, "Sterilization procedures of foods-principle, characteristics, present situation and subject (2) outline of methods for killing of microorganisms," Journal of
Antibacterial and Antifungal Agents, vol. 36, no. 6, pp. 403409, 2008, (in Japanese).

[7] T. Arai, "Sterilization procedures of foods-principle, characteristics, present situation and subjects (11) physical procedures (3)-sterilization of foods with superheated steam," Journal of Antibacterial and Antifungal Agents, vol. 37, no. 3, pp. 203-210, 2009, (in Japanese).

[8] J. H. Lee, T. H. Sung, K. T. Lee, and M. R. Kim, "Effect of gamma-irradiation on color, pungency, and volatiles of Korean red pepper powder," Journal of Food Science, vol. 69, no. 8, pp. C585-C592, 2004.

[9] S. Yonemori, Y. Nakagawa, R. Ono, and T. Oda, "Measurement of $\mathrm{OH}$ density and air-helium mixture ratio in an atmospheric-pressure helium plasma jet," Journal of Physics D: Applied Physics, vol. 45, no. 22, Article ID 225202, 2012.

[10] A. Komuro, R. Ono, and T. Oda, "Behaviour of $\mathrm{OH}$ radicals in an atmospheric-pressure streamer discharge studied by twodimensional numerical simulation," Journal of Physics D: Applied Physics, vol. 46, no. 17, Article ID 175206, 2013.

[11] D. Riès, G. Dilecce, E. Robert, P. F. Ambrico, S. Dozias, and J.-M. Pouvesle, "LIF and fast imaging plasma jet characterization relevant for NTP biomedical applications," Journal of Physics D: Applied Physics, vol. 47, no. 27, Article ID 275401, 2014.

[12] T. Yuji, H. Kawano, S. Kanazawa, T. Ohkubo, and H. Akatsuka, "Laser-induced fluorescence image of $\mathrm{OH}$ radicals for atmospheric-pressure nonequilibrium dry air gas DC pulse plasma jet," IEEE Transactions on Plasma Science, vol. 36, no. 4, pp. 976-977, 2008.

[13] M. Laroussi, "Sterilization of contaminated matter with an atmospheric pressure plasma," IEEE Transactions on Plasma Science, vol. 24, no. 3, pp. 1188-1191, 1996.

[14] G. Fridman, G. Friedman, A. Gutsol, A. B. Shekhter, V. N. Vasilets, and A. Fridman, "Applied plasma medicine," Plasma Processes and Polymers, vol. 5, no. 6, pp. 503-533, 2008.

[15] J. Ehlbeck, U. Schnabel, M. Polak et al., "Low temperature atmospheric pressure plasma sources for microbial decontamination," Journal of Physics D: Applied Physics, vol. 44, no. 1, p. 13002, 2011.

[16] S. Bekeschus, P. Favia, E. Robert et al., "White paper on plasma for medicine and hygiene: future in plasma health sciences," Plasma Processes and Polymers, vol. 16, Article ID e1800033, 2019.

[17] A. Stancampiano, T. Gallingani, M. Gherardi et al., "Plasma and aerosols: challenges, opportunities and perspectives," Applied Sciences, vol. 9, no. 18, p. 3861, 2019.

[18] H. Cheng, J. Xu, X. Li, D. Liu, and X. Lu, "On the dose of plasma medicine: equivalent total oxidation potential (ETOP)," Physics of Plasmas, vol. 27, no. 6, Article ID 063514, 2020.

[19] T. Yuji, Y. Suzaki, T. Yamawaki, I. Matsushima, and H. Akatsuka, "Optical emission spectroscopy of atmosphericpressure non-equilibrium DC pulse discharge plasma jets and PEN film surface modification," Journal of High Temperature Society, vol. 33, no. 3, pp. 137-141, 2007, (in Japanese).

[20] E. Robert, V. Sarron, D. Riès, S. Dozias, M. Vandamme, and J.-M. Pouvesle, "Characterization of pulsed atmosphericpressure plasma streams (PAPS) generated by a plasma gun," Plasma Sources Science and Technology, vol. 21, no. 3, Article ID 034017, 2012.

[21] Z. Xiong and M. J. Kushner, "Atmospheric pressure ionization waves propagating through a flexible high aspect ratio capillary channel and impinging upon a target," Plasma 
Sources Science and Technology, vol. 21, no. 3, Article ID 034001, 2012.

[22] T. Yuji, Y. Suzaki, T. Yamawaki, H. Sakaue, and H. Akatsuka, "Experimental study of temperatures of atmospheric-pressure nonequilibrium $\mathrm{Ar} / \mathrm{N}_{2}$ plasma jets and poly (ethylene terephtalate)-surface processing," Japanese Journal of Applied Physics, vol. 46, no. 2, pp. 795-798, 2007.

[23] T. Yuji, S. Fujii, N. Mungkung, and H. Akatsuka, "Optical emission characteristics of atmospheric-pressure nonequilibrium microwave discharge and high-frequency DC pulse discharge plasma jets," IEEE Transactions on Plasma Science, vol. 37, no. 6, pp. 839-845, 2009.

[24] R. W. Reed and G. B. Reed, "Drop plate" method of counting viable bacteria," Canadian Journal of Research, vol. 26e, no. 6, pp. 317-326, 1948.

[25] C. Welinder-Olsson and B. Kaijser, "Enterohemorrhagic Escherichia coli (EHEC) scandinavian," Journal of Infectious Diseases, vol. 37, no. 6-7, pp. 405-416, 2005.

[26] W. A. Petri Jr., M. Miller, H. J. Binder, M. M. Levine, R. Dillingham, and R. L. Guerrant, "Enteric infections, diarrhea, and their impact on function and development," Journal of Clinical Investigation, vol. 118, no. 4, pp. 1277-1290, 2008.

[27] E. F. Dixon and R. A. Hall, "Noisy neighbourhoods: quorum sensing in fungal-polymicrobial infections," Cellular Microbiology, vol. 17, no. 10, pp. 1431-1441, 2015.

[28] J. P. Nataro and J. B. Kaper, "Diarrheagenic Escherichia coli," Clinical Microbiology Reviews, vol. 11, no. 1, pp. 142-201, 1998.

[29] H. Narayana and S. V. S. Setty, "Studies on the incorporation of mulberry (Morus indica) leaves in layers mash on health, production and egg quality," Indian Journal of Animal Science, vol. 47, no. 4, pp. 212-215, 1977.

[30] T. Yuji, N. Mungkung, H. Kawano, S. Kanazawa, T. Ohkubo, and H. Akatsuka, "Laser-induced fluorescence detection of $\mathrm{OH}$ radicals generated by atmospheric-pressure nonequilibrium DC pulse discharge plasma jets," IEEE Transactions on Plasma Science, vol. 42, no. 4, pp. 960-964, 2014.

[31] W. A. Micmahon, V. A. Aleo, A. M. Schultz, B. L. Horter, and K. G. Lindberg, " $3 \mathrm{M}^{\mathrm{TM}}$ petrifilm ${ }^{\mathrm{TM}}$ staph express count plate method for the enumeration of Staphylococcus aureus in selected types of meat, seafood, and poultry: collaborative study," Journal of AOAC International, vol. 86, no. 5, pp. 947-953, 2003.

[32] I. A. Kossyi, A. Y. Kostinsky, A. A. Matveyev, and V. P. Silakov, "Kinetic scheme of the non-equilibrium discharge in nitrogen-oxygen mixtures," Plasma Sources Science and Technology, vol. 1, no. 3, pp. 207-220, 1992.

[33] J. H. Choi, I. Han, H. K. Baik et al., "Analysis of sterilization effect by pulsed dielectric barrier discharge," Journal of Electrostatics, vol. 64, no. 1, pp. 17-22, 2006.

[34] P. Attri, Y. H. Kim, D. H. Park et al., "Generation mechanism of hydroxyl radical species and its lifetime prediction during the plasma-initiated ultraviolet (UV) photolysis," Scientific Reports, vol. 5, no. 1, p. 9332, 2015. 